\title{
EL VALOR PATRIMONIAL DE LA ARQUITECTURA VIRREINAL
}

\author{
Antonio San Cristóbal Sebastián*
}

\section{CONSIDERACIONES CONCEPTUALES}

La denominación común de "patrimonio cultural", aplicada también -entre otras varias objetividades culturales- a la arquitectura virreinal peruana, tiene para la generalidad de la gente un significado cultural expresado como mera referencia. El objeto reconocido oficialmente como cultural, en este caso la arquitectura virreinal, se califica con relación a una cultura con la que se supone que está identificado y a la que representa, y cuya conservación y decoroso mantenimiento imponen algunas obligaciones jurídicas que pueden ser cumplidas o vulneradas. Es un modo de presentación genérica del objeto considerado como cultural, para que su conocimiento se extienda a círculos cada vez más amplios de actuales o de futuros espectadores. Como pura denominación de efectos jurídicos, el título de patrimonio cultural puede ser otorgado, renovado o anulado sin que se altere en ningún aspecto la inserción del objeto en una determinada cultura.

Diríamos que la denominación de patrimonio cultural exige una doble relación independiente: con los hombres que otorgan y reconocen este título y con la cultura a la que pertenece el objeto. Asumimos en lo sucesivo esta segunda referencia.

Nos preguntamos ahora acerca de la manera en que la arquitectura virreinal peruana todavía existente expresa una cultura con relación a la cual puede ser calificada como patrimonio cultural.
Por lo pronto distinguimos entre la cultura en la que surgió y fue construida y utilizada, y la cultura vigente en nuestro tiempo. A lo largo de unos tres siglos de intervalo entre ambas concepciones culturales han variado profundamente los valores, los sentimientos colectivos, las normas sociales y otros ingredientes de cada una de estas dos situaciones culturales, aun cuando la cultura virreinal pueda ser considerada como uno de los antecedentes históricos, acaso ya bastante lejanos, de la cultura contemporánea.

La arquitectura virreinal ha perdurado en uso, al menos en los monumentos que hoy la representan, a lo largo de todos los cambios culturales. Si en sus orígenes, siglos XVI al XVIII, constituía parte integrante y representativa de la vida cultural, en los tiempos actuales esa misma arquitectura virreinal -de plena utilización en los monumentos religiosos- es considerada como perteneciente al patrimonio cultural heredado de la época virreinal.

Desde el punto de vista objetivo se trata de la misma arquitectura virreinal con referencia a ambas situaciones culturales distanciadas y diferenciadas entre sí como la cultura propia de cada tiempo. Pero desde la perspectiva de nuestro conocimiento actual, la arquitectura virreinal presenta dos expresiones o maneras según se refiera a la cultura virreinal en que surgió o a la cultura contemporánea en que es apreciada. La arquitectura virreinal fue elaborada en un tiempo histórico determinado, según los criterios estilísticos, 
las técnicas constructivas, los materiales y las concepciones arquitectónicas que entonces estaban vigentes, y que crearon y aplicaron los alarifes virreinales, sus constructores.

Sobre la realidad objetiva de la arquitectura virreinal conservada en nuestro tiempo se superponen las interpretaciones historiográficas formuladas por los diferentes y a veces antagónicos expositores. Diríamos que se trata del recubrimiento historiográfico con que los teóricos que han tratado de analizarla y de interpretarla nos la presentan. Ya no consiste en la pura desnudez de esa arquitectura en su conformación objetiva, sino a su interpretación según las concepciones en las que se instala previamente cada historiógrafo. De ello deriva que podamos hablar de diversas versiones teóricas superpuestas a la arquitectura virreinal objetiva: la definimos como la arquitectura virreinal teórica, es decir, como objeto de las teorías científicas.

En verdad, el valor de patrimonio cultural asignado a la arquitectura virreinal -aun cuando incluye la arquitectura virreinal como objeto histórico- no se atribuye directamente a la arquitectura inserta en la cultura virreinal objetiva con su cultura correlativa, vigente durante los siglos ya mencionados, ya que esta conexión ha sido desplazada en nuestro tiempo por las versiones de la arquitectura interpretadas por los teóricos actuales; y esta segunda expresión es la que adquiere el carácter de patrimonio cultural.

Tengamos en cuenta además que la arquitectura virreinal -construida originalmente en conexión directa con las concepciones culturales de su tiempo y con las experiencias sociales y económicas de los hombres para los que se erigió- ha sido reducida y modificada por las diversas actuaciones que sobre ella han recaído. Fue afectada en algunos centros regionales por terremotos destructores, modificados posteriormente durante el mismo período virreinal por reconstrucciones $y$ añadiduras; en otros regionales una parte muy importante de ella ha sido destruida por los agentes naturales o por los hombres.

Señalamos brevemente algunas de las transformaciones sufridas por la arquitectura virreinal.
Hasta el terremoto de 1687 las iglesias limeñas estaban cubiertas con bóvedas vaídas de crucería, labradas con cal y ladrillo y con alfarjes mudéjares de madera desplegados en tres o en cinco paños; actualmente esas mismas iglesias muestran como cubiertas unas bóvedas de medio cañón con lunetos más o menos perfectamente labradas, conformadas por cerchas de madera y recubiertas con una capa de cañas y yeso.

Algunos historiadores $\sin$ base documental segura consideran las bóvedas de la iglesia del conjunto de San Francisco como las que fueron terminadas al inaugurarse este hacia 1672; pero esos mismos historiadores convencionales omiten mencionar que esas bóvedas primigenias de cal y ladrillo se hundieron con el terremoto de 1687 y que, consiguientemente, las bóvedas franciscanas actuales proceden de la primera década del siglo XVIII.

Las bóvedas de la Catedral Metropolitana de Lima han sido reconstruidas sucesivamente después de los terremotos de 1687 y de $1746, y$ las bóvedas catedralicias actuales datan del período republicano -por los años de 1896 a 1898-y fueron inauguradas por el presidente Piérola.

Otras valiosas iglesias como la del monasterio de la Concepción, la del monasterio de la Encarnación, la de Santa Teresa o El Carmen Bajo, la jesuítica de Los Desamparados, el hospital de la Caridad, el hospital de San Bartolomé, La Recoleta mercedaria de Belén, el colegio franciscano de Guadalupe, la iglesia del colegio agustiniano de San Ildefonso, etc., han desaparecido de la planta y traza urbana de la Ciudad de los Reyes del Perú, hoy Patrimonio Cultural de la Humanidad. Las iglesias de los monasterios de Santa Catalina, de la Santísima Trinidad y de las Descalzas Concepcionistas de San Joseph ofrecen actualmente un aspecto arquitectónico muy distinto del que lucieron durante todo el siglo XVII, después de su construcción.

Nos hemos referido solamente a la arquitectura de obra firme, pero las diferencias afectan en grado extremo la arquitectura de los retablos virreinales limeños, que constituyen otra de las grandes expresiones del patrimonio cultural de 
la época. Iglesias enteras han sido despojadas de los retablos barrocos salomónicos y solo se puede admirar actualmente algunos de los retablos de los siglos XVII y XVIII en la iglesia de Jesús María, la de Santa María Magdalena en Pueblo Libre, la de San Pedro, y aquellos trasladados a la catedral de Lima.

De lo expuesto se deduce que la arquitectura de estas iglesias y conventos solo corresponde en parte y con modificaciones ulteriores a la construida en conexión directa con su propia cultura virreinal. Las bóvedas de medio cañón con ventanales rectangulares, labradas con la popular quincha -existentes en algunas iglesias limeñas-corresponden a un patrimonio cultural distinto del que labró las bóvedas vaídas de crucería con cal y ladrillo y los alfarjes mudéjares de madera en esas mismas iglesias.

Las diferencias cuantitativas y cualitativas que interceden entre la arquitectura virreinal objetiva construida y utilizada durante los siglos XVII y XVIII de una parte, $y$ de la otra la arquitectura virreinal que ahora conservamos y utilizamos, solo pueden salvarse mediante el recurso de las investigaciones históricas y arquitectónicas que incrementen y a la vez corrijan el conocimiento sobre la arquitectura virreinal originaria que fue construida o reconstruida en su propio tiempo; y que además permitan sacar a luz las carencias actuales $y$ las modificaciones deformadoras que ofrece ahora la arquitectura objetiva existente.

El valor de patrimonio cultural asignado a la arquitectura virreinal existente está sujeto a una evolución progresiva en su contenido conceptual, en la medida en que se incremente el conocimiento científico sobre ella tal como fue construida y existió durante los siglos XVII y XVIII. Es un conocimiento científico sobre la arquitectura objetiva que inicialmente se construyó, pero que se proyecta hacia la arquitectura virreinal actualmente existente para determinar lo que nosotros entendemos desde nuestra situación contemporánea acerca de la arquitectura virreinal calificada como patrimonio cultural. Vuelve así a reaparecer la distinción antes establecida entre la arquitectura virreinal objetiva y la arquitectura virreinal teórica.
Para una mayor precisión conceptual en la exposición de los apartados siguientes empleamos ahora estas otras denominaciones:

Arquitectura virreinal originaria: Entendemos por tal la que fue construida durante los siglos XVII y XVIII según las características de la vigencia del barroco en todas las expresiones de la vida humana y social.

Arquitectura patrimonial: Comprende la arquitectura que ahora se conserva, completada con las interpretaciones historiográficas que han propuesto los intérpretes; a ella se le atribuye el concepto de patrimonio cultural.

Sería muy conveniente que esta arquitectura patrimonial progresara en su ámbito mediante el conocimiento teórico, hasta aproximarse en la mayor medida posible a lo que fue la arquitectura virreinal originaria. Pero advertimos que solo puede lograrse este progreso en el plano del conocimiento interpretativo, no en cuanto a la arquitectura objetiva; porque la arquitectura virreinal ahora existente ya no puede retornar o reactualizar lo que fue la originaria, por las destrucciones, modificaciones y deformaciones que la han transformado notablemente en relación con lo que se construyó.

\section{INTERPRETACIONES SOBRE LA ARQUITECTURA PATRIMONIAL}

No se pretende exponer ahora todas las interpretaciones formuladas sobre la arquitectura virreinal peruana, de las que me he ocupado en un libro dedicado a este tema historiográfico' ${ }^{1}$. Se mencionan tan solo las tendencias historiográficas que orientan a presentar un concepto de la arquitectura virreinal considerada como patrimonio cultural. La pregunta consistiría ahora en averiguar de qué manera algunas interpretaciones teóricas consideran el patrimonio cultural que identificamos con la arquitectura virreinal peruana.

Las primeras investigaciones históricas acerca de la arquitectura virreinal peruana se remontan a la década de 1940. Algunos investigadores 
acopiaron y publicaron informaciones de archivo dispersas y poco numerosas, más bien a modo de noticias escuetas que como exposiciones amplias y completas sobre los monumentos virreinales. Este proceso de acopio y de divulgación del material histórico asumido de las fuentes documentales de archivo terminó aproximadamente hacia 1950, aunque algunos trabajos se publicaran muchos años después, como el libro de Harth-Terré sobre los escultores españoles en el virreinato, que se editara tardíamente (1977).

La generación siguiente, integrada por los ahora denominados historiadores sistemáticos, recopiló todas las informaciones procedentes de las fuentes archivísticas publicadas hasta 1950, cuando cesó la investigación directa documental. Contando solo con tan escasas, dispersas e inseguras informaciones, se lanzaron a formular una interpretación a modo de sistema general sobre el desarrollo de la arquitectura virreinal en su desenvolvimiento histórico. Era una primera presentación sistematizada acerca del patrimonio cultural que, según ellos lo entendían, ofrecía la arquitectura virreinal al conocimiento y apreciación de los contemporáneos interesados por ella.

Podemos mencionar, sin abarcar totalmente el tema, el tratado clásico de H.E. Wethey, publicado en $1949^{2}$, y la tesis doctoral de Jorge Bernales Ballesteros en Sevilla ${ }^{3}$ sobre la arquitectura limeña de 1972. Ambos mencionan y utilizan las mismas informaciones documentales acopiadas hasta el año de 1950, pero no amplían con nuevas noticias de archivo lo hasta entonces conocido y publicado. En realidad estos tratados sistemáticos produjeron un verdadero estancamiento y paralización en los estudios históricos sobre la arquitectura virreinal peruana, pues los escritores posteriores los consideraron como definitivos y tampoco se preocuparon por incrementar los conocimientos consignados en ellos. Se ha creado así una intermediación que desplaza al olvido completo los documentos conservados en los archivos de fondos virreinales porque los estudiosos posteriores han considerado las informaciones acopiadas hasta 1950 -junto a las publicaciones relacionadas con ellasy las de los sistemáticos como las fuentes primarias a las que reiteradamente recurren para conocer la arquitectura virreinal. Diríamos que el patrimonio cultural se ha encerrado en un horizonte estrecho y rígidamente cercado, abarcando el estudio de la arquitectura virreinal solo hasta las investigaciones terminadas en el año en mención.

La validez de este sistema histórico general así fundamentado se sustentaba en los escasos, dispersos e inseguros apoyos informativos hasta entonces acumulados, y también en las amplias lagunas vacías de informaciones históricas extendidas por períodos cronológicos muy prolongados y sumidas en la oscuridad documental, intercaladas entre las raleadas noticias históricas manejadas por los historiadores sistemáticos. Fuera de estos sistemas generales quedaban las amplísimas y más fundamentales informaciones históricas consenvadas en los archivos y todavía inexploradas por dichos historiadores.

Baste citar un ejemplo paradigmático. Estos historiadores de los sistemas generales hacen terminar el período de influencia mudéjar sobre la arquitectura limeña en 1602, con la concertación del alfarje para la iglesia del monasterio de la Concepción, a pesar de que posteriormente he descubierto las informaciones de archivo no conocidas por Wethey y Bernales Ballesteros por las que consta que tres generaciones sucesivas de carpinteros mudéjares construyeron durante la primera mitad del siglo XVII hasta 25 alfarjes mudéjares de cinco paños, entre los años de 1602 y 1656 , es decir a un promedio de un alfarje cada dos años, durante medio siglo continuo.

Nos interesa señalar qué clase de arquitectura patrimonial presentaban los historiadores sistemáticos. Por lo pronto se trataba de una arquitectura muy reducida y simplificada en comparación con la arquitectura virreinal originaria - $\mathrm{e}$ incluso también en relación con la arquitectura virreinal que actualmente se conserva-, ya que la somera documentación informativa que manejaban no explicaba la construcción de estos

2 H.E. Wethey. Colonial architecture and sculpture in Peru. Massachusetts, Cambridge, Harvard Universily Press, 1949.

3 Jorge Bernales Ballesteros. Lima, la ciudad y sus monumentos. Sevilla, CSIC, 1972. 
monumentos todavía existentes. Por consiguiente, entre la que hemos denominado antes como arquitectura patrimonial y la que realmente exponían los historiadores sistemáticos mencionados no había ninguna correspondencia, dada la insuficiencia y simplicidad de esta última.

En segundo lugar, a falta de un conocimiento arquitectónico amplio sobre las estructuras compositivas, recurrieron estos historiadores sistemáticos a la transferencia de los estilos europeos clásicos hacia la arquitectura virreinal, un patrimonio cultural estilístico asumido de las arquitecturas europeas. Era una forma todavía implícita de considerar la arquitectura virreinal como culturalmente dependiente de la arquitectura española, y como una extensión patrimonial de esta; se trataba además de una dependencia formal, en cuanto que los estilos artísticos son formas genéricas que solo adquieren expresión en las estructuras compositivas, sobre las que los historiadores sistemáti$\cos$ no formularon exposiciones adecuadas, antes bien las soslayaron.

La interpretación de la arquitectura virreinal patrimonial como dependiente fue propuesta de un modo explícito durante las décadas de 1960 a 1980, en un momento historiográfico posterior al de los sistemáticos. Los historiógrafos de esta nueva generación dejaron de lado la tarea de ampliar las investigaciones históricas, que habían quedado paralizadas desde 1950 , pues no tomaron conocimiento de un solo documento de archivo anteriormente inexplorado. En sus planteamientos se dedicaron a encaminar la arquitectura virreinal objetiva -la única que ellos conocieron-por la senda de la dependencia, hacia una diversificación geográfica más amplia de arquitecturas europeas donde las transmisiones culturales de sus modelos habían impactado sobre la arquitectura virreinal.

El iniciador de esta tendencia historiográfica fue el norteamericano George Kubler, quien se esforzó por abrir algunos forados en las fronteras del imperio artístico español, a través de los cuales introduciría después algunos aportes europeos no-ibéricos a ser usados en la arquitectura virreinal hispanoamericana ${ }^{4}$.

Lo que todavía en Kubler no era más que una complementación de los aportes españoles con otros europeos no-ibéricos, recibidos ambos por la arquitectura virreinal, se metamorfoseó en los escritos de Graciano Gasparini en una teoría que propugnaba la situación generalizada de dependencia de la arquitectura virreinal en cuanto estaba constreñida a recibir los aportes de los modelos transmitidos sucesivamente desde las arquitecturas llamadas "cultas" europeas en general: la española y las europeas no-ibéricas ${ }^{5}$.

Esta teoría historiográfica de la dependencia incluye al menos implícitamente algunas implicaciones fundamentales en cuanto al contenido conceptual de la arquitectura virreinal patrimonial. Por lo pronto reduce al mínimo la creatividad y la originalidad que competía a los alarifes virreinales, pues presupone que los modelos que aplicaban no fueron creados por ellos, sino recibidos por transmisiones extremas desde los centros creadores europeos a los que esta teoría parece reservar la exclusividad de instaurar lo que posteriormente se aplicaría en la arquitectura virreinal.

En segundo lugar, de esta teoría de la dependencia se deduciría que el patrimonio a que corresponde culturalmente la arquitectura virreinal deja de ser la expresión de la cultura de su época, pues estaría imbuido de la expresión cultural que portaban los aportes europeos recibidos y aplicados: de una parte la cultura de los aportes españoles y de otra la de los aportes europeos no-ibéricos. Resultaría lógico deducir que la arquitectura virreinal viene a ser un patrimonio virreinal solamente en cuanto se asentaba en el virreinato del Perú, pero su contenido cultural no habría surgido por la creación de los hombres virreinales peruanos, sino mediante la transmisión de los aportes europeos en general, desde los centros creadores del viejo continente. 
Esta versión historiográfica está representada muy fielmente en la que fue la tesis doctoral de llmar Luks en la Universidad de Heidelberg, que buscaba las fuentes documentales gráficas para los motivos escultóricos tallados en la arquitectura planiforme surperuana del siglo XVIII y recurría para ello a los grabados, ilustraciones de libros y monumentos europeos, de los que presuntamente los talladores andinos habrían acopiado e imitado la decoración que aplicaron en sus portadas planiformes ${ }^{6}$. Defendía el escritor Luks la siguiente teoría:

"La escultura decorativa andina resulta ser una imitación popular del arte 'culto' europeo transmitido a los centros culturales coloniales y de carácter netamente regional. Inspirados en un único propósito artístico-religioso, sus autores no se hallan ni mental, ni técnicamente capacitados para ejecutar la obra, tal como aparece en el arte 'culto' europeo... Todo el arte colonial está estrechamente ligado a las categorías tipológicas del arte europeo, menos en las técnicas de ejecución y conserva un notable grado de espontaneidad. Dicha espontaneidad no significa, por cierto, el sentido de libertad inventiva"7.

Naturalmente que esta tesis historiográfica propuesta por Ilmar Luks carece de todo sustento confiable y científico, por la simple razón -anotada ya por Ramón Gutiérrez en su ponencia al Simposio de Roma de 1980-de que las fuentes gráficas a las que recurre no llegaron en absoluto a las bibliotecas virreinales peruanas de la zona andina, y por consiguiente eran totalmente desconocidas $\mathrm{e}$ inaccesibles para los talladores andinos planiformes, e incluso para los párrocos de las iglesias con portadas ornamentadas con modelos escultóricos. $Y$, desde luego, los abundantes motivos ornamentales asumidos de la flora y la fauna autóctonas que recubren en gran número esas portadas planiformes andinas no proceden en $a b-$ soluto de fuentes europeas, aunque Luks no ha caído en cuenta de ello.
Además de todo lo expuesto, este escritor no se fundamenta para nada en la investigación de las fuentes de archivo de fondos virreinales para conocer cómo y de dónde se formaron los modelos aplicados en la arquitectura andina planiforme, sino tan solo en la tesis sociológica de la dominación, en base a la cual restringe a priori toda capacidad de creación original en los artífices virreinales. Por eso, y solamente desde este presupuesto sociológico, les niega toda capacidad de creación original: "la libertad expresiva nunca existió en el arte colonial" 8 . En realidad, debería haber escrito: "yo presupongo sin fundamento alguno que la libertad expresiva nunca existió en el arte colonial", frase más acorde con su tesis sociológica. Lo único que sucedía es que sus prejuicios ideológicos no le permitían reconocer la existencia objetiva de la plena libertad creadora con la que actuaban los artífices virreinales peruanos.

Añadamos todavía esta otra observación de fondo: La tesis de la dependencia cultural, por la recepción de los modelos europeos, sobrepuesta a la arquitectura virreinal peruana -prescindiendo de lo que atañe a las otras arquitecturas virreinales hispanoamericanas-, se queda en un simple esquema formal, vacío de contenido objetivo determinado y constatado. Ello debido a que esta tesis historiográfica no ha señalado cuáles fueron esos modelos europeos recibidos y aplicados en monumentos concretos de la arquitectura virreinal peruana, y tampoco ha precisado de qué fuentes europeas concretas y determinadas proceden esos presuntos e inexpresados modelos transmitidos. He analizado ampliamente el tema concreto de los arcos abiertos de cornisa difundidos en las portadas y los retablos virreinales peruanos que, lejos de proceder de las fuentes europeas asignadas por los historiógrafos europeocéntricos -como serían los grabados de Wendel Dietterlin o los retablos sevillanos-, constituyen una auténtica creación original producida por los alarifes y ensambladores virreinales radicados en el Perú9.

IImar Luks. "Tipologia de la escultura decorativa hispánica en la arquitectura andina del siglo XVIII". En BCIHE 17, Caracas, 1973.

thidern, pp. 43 y 44 .

Hidem, p. 25.

Antonio San Cristobal. Estructuras omamentales de la arquitectura virreinal peruana. Lima, Facultad de Arquitectura, Universidad Nacional de Ingenieria, 2002, pp. 63 -138. 
En otras arquitecturas virreinales hispanoamericanas, como las de Bogotá, Quito, Chile o Argentina, los alarifes o ensambladores religiosos europeos trabajaron como agentes transmisores de los modelos aplicados previamente en sus países de origen. Por el contrario, desde el segundo tercio del siglo XVII, cuando la arquitectura virreinal peruana iniciaba el decidido proceso de su diferenciación autónoma respecto de las arquitecturas europeas, no aparece ninguno de estos alarifes actuando en ella -fueran españoles o europeos no-ibéricos-; solo consta documentalmente la participación activa de artífices avecindados y formados profesionalmente en el Perú virreinal, quienes expresaron en sus construcciones arquitectónicas de obra firme y de retablos de madera dorada la cultura de la sociedad virreinal en la que vivían y actuaban, y nos han legado en sus obras el patrimonio cultural de su época.

Todas estas prolijas dilucidaciones historiográficas confluyen hacia una misma concepción de la arquitectura virreinal peruana como patrimonio cultural. En las historiográficas europeístas de las distintas tendencias, la arquitectura virreinal representaría de un modo más o menos explícito el patrimonio cultural europeo de donde habría procedido la transmisión de los modelos formales expresados objetivamente en los monumentos virreinales. Frente a las tesis europeocéntricas, venimos exponiendo en nuestras publicaciones la tesis de la autonomía de la arquitectura virreinal peruana, según la cual esta alcanzó desde mediados del siglo XVII su diferenciación específica respecto de las arquitecturas europeas en su conjunto; $y$ por consiguiente esta arquitectura virreinal autónoma y específica representa el patrimonio cultural de las concepciones del mundo y de la vida profesadas en la sociedad cultural del virreinato, según las distintas épocas de su desarrollo histórico. Desde luego hay diferencias entre la expresión cultural correspondiente al gran barroco cuzqueño de la segunda mitad del siglo XVII y la cultura en que surgió la torre solitaria del convento de Santo Domingo, reconstruida en tiempos del virrey Amat.

\section{LA ARQUITECTURA VIRREINAL COMO RETÓRICA PERSUASIVA}

Algunos de los concurrentes al Simposio de Roma asumieron la interpretación de la arquitectura virreinal como retórica persuasiva de una concepción de vida cultural, sobre la base de los planteamientos de algunos círculos culturalistas europeos acerca de las relaciones entre el barroco y la retórica. No es una versión centrada directamente sobre la arquitectura virreinal peruana, sino más bien transferida hacia su interpretación desde ciertos planteamientos sobre la función retórica desempeñada por las altas clases sociales laicas en medios culturales barrocos, cuyo comportamiento ostensible transmitía supuestamente un modo de vida y una concepción cultural a la sociedad circundante. Salvadas las diferencias entre las clases sociales barrocas europeas y la arquitectura virreinal, algunos expositores han sustentado un proceso similar de transición -a modo de retórica silenciosa y objetiva de unos ideales de vida difundidosdesde las expresiones más decorativas de la arquitectura virreinal, como son las portadas y los retablos, hacia los ciudadanos que las contemplaban diariamente.

Esta interpretación retórica fue propuesta en el Simposio de Roma por Graciano Gasparini, Jorge Bernales Ballesteros y Santiago Sebastián, asumiendo del barroco la superficialidad exteriorizada del lujo, del refinamiento de las costumbres, de la ornamentalidad en el vestuario y en el actuar público, de las fiestas de arraigo popular $y$ de todas las manifestaciones que podían exteriorizar hacia los demás un comportamiento ostensible. En todos estos modos costumbristas actuaría una retórica difusión de los ideales de vida socialmente compartidos. Se considera que un comportamiento similar atribuido a las portadas y a los retablos virreinales del período barroco también habría actuado como retórica persuasiva de la religiosidad popular.

El barroco incrementó ciertamente el revestimiento decorativo de estas estructuras arquitectónicas bajo formas muy diferenciadas según las regiones virreinales $y$ se supone que este desbordamiento decorativo de las portadas y de los retablos reiteraba una ostentación similar a la de 
las clases en la sociedad barroca; y que por consiguiente a su semejanza transmitirian por persuasión retórica el mensaje cultural religioso. La arquitectura de los retablos y de las portadas virreinales barrocas impresionaba retóricamente la imaginación y los sentimientos más espontáneos de los ciudadanos corrientes y comunes; y mediante esta influencia suscitarian en ellos la aceptación de las creencias y de las normas de vida religiosa.

En esta interpretación retórica de la arquitectura virreinal también está implícitamente contenido un concepto de la arquitectura como patrimonio cultural. No se refiere a lo que la arquitectura virreinal sea en sí misma y por su propia conformación estructural, sino a la función instrumental que se le atribuye como propagadora de una cultura religiosa vivida, comunicada y aceptada según el modo barroco de la ostentación decorativa: sería una arquitectura culturalmente persuasiva y transmisora de la concepción cultural religiosa, más propiamente que expresión de la arquitectura como arte y técnica de la construcción ornamentada.

Para interpretar en sus justos términos esta versión de patrimonio cultural que correspondería atribuir a la arquitectura virreinal entendida ahora como retórica persuasiva, conviene precisar en primer término de qué manera habría desempeñado esta arquitectura barroca la funcionalidad de propagadora de una concepción cultural de la vida.

Señalemos, por lo pronto, que el ejercicio de la retórica persuasiva ha estado vinculado a la cultura del período barroco. Primero en el comportamiento social de las clases altas más influyentes y luego transferido a la ostentación barroca de las portadas y de los retablos virreinales peruanos. No se pone en duda que haya existido una comunicación retórica de los comportamientos culturales ejercida mediante la persuasión, derivada de la ostentación decorativa de las personas y también de los monumentos barrocos. De lo que ahora se trata es de precisar si este ejercicio retórico constituye la razón primaria y fundamental de la presencia pública de la arquitectura virreinal.
En una simple mirada general encontramos cierta desconexión entre la arquitectura virreinal, que en su conjunto es un verdadero patrimonio cultural, y la función sociológica de la persuasión retórica que habría ejercido durante el período barroco. La arquitectura virreinal peruana fue desarrollada desde el último tercio del siglo XVI hasta que irrumpió destructoramente el neoclásico a finales del siglo XVIII. Durante este largo periplo evolucionó en etapas diferenciadas según los estilos artísticos. La arquitectura inicial, prolongada en algunas regiones hasta mediados del siglo XVII, siguió la tendencia estilística del renacimiento y en parte del manierismo; de ello quedan algunos monumentos muy característicos, como la iglesia del convento agustiniano de Guadalupe, y portadas y retablos dispersos en distintas zonas geográficas, como las portadas de Paucarcolla, Chucuito, Acora, llave y La Asunción de Juli en el Collao, además de hermosos retablos renacentistas en pueblos de Huancayo, del Cuzco y del Collao. La etapa del barroco es $\sin$ duda la más prolongada de la arquitectura virreinal peruana y la que muestra mayor ostentación decorativa; a ella siguió, especialmente en Lima, una etapa ulterior del rococó que si bien no abarcó exclusivamente la segunda mitad del siglo XVIII, dejó algunas construcciones representativas, como los dos cuerpos superiores de la torre de Santo Domingo y el baptisterio en la iglesia de Los Huérfanos.

Los historiógrafos culturalistas no han concentrado la función retórica persuasiva sobre toda la arquitectura virreinal en su conjunto, cronológicamente tan prolongada, sino que suponen que fue ejercitada desde la arquitectura barroca en paralelo con la influencia persuasiva que ejercían sobre la sociedad virreinal, a modo de persuasión, las clases sociales altas imbuidas de la fastuosa ostentación barroca.

Desde luego no atribuyen el ejercicio de la retórica persuasiva a la arquitectura de la etapa renacentista, a pesar de que en este período existieron retablos ostentosos y portadas exteriores en las iglesias, y de que la concepción de vida de los hombres virreinales se inspiraba también en las ideas y costumbres sociales de sentido religioso. Solo confieren funcionalidad retórica a las 
portadas y a los retablos del período barroco virreinal. De este modo, el patrimonio cultural consistente en la arquitectura barroca virreinal habría sustentado una irradiación de retórica persuasiva, no como tal patrimonio, ni tampoco como tal obra arquitectónica de función irradiadora desde la cultura virreinal en su conjunto, sino en virtud de algunas características arquitectónicas estructurales y ornamentales asumidas por la arquitectura virreinal durante la vigencia del período barroco.

Pero esta correlación entre la arquitectura barroca en cuanto patrimonio cultural y la retórica persuasiva de un modo de vida suscitan algunas aporías difíciles de solventar. En primer término indicamos que la arquitectura virreinal peruana está diferenciada en escuelas regionales tan disímiles como la del Cuzco, la de Lima, la de Arequipa-Collao y la de Cajamarca. Sin embargo la cultura social, los valores y las normas del comportamiento religioso eran unívocos y del mismo contenido ideológico y sentimental para los habitantes de todo el virreinato del Perú. Existiría, pues, un antagonismo entre la heterogeneidad de la arquitectura virreinal persuasora -patrimonio cultural- y la homogeneidad del mensaje cultural persuadido retóricamente desde ella. No se comprende fácilmente por qué razones tendría que transmitirse la misma concepción de vida en unos casos desde una arquitectura decorativa tan sobria como la limeña del siglo XVIII, y en otros casos desde la desbordante ornamentalidad de plenitud total como es la de Cajamarca, a no ser que la cultura barroca de los limeños fuera más sobria que la de los cajamarquinos por la misma época.

Aparece también como aporético el contraste en cuanto a la difusión de la cultura virreinal homogénea y el despliegue tan diferenciado de la arquitectura persuasiva difusora. En ciudades como Lima, Cuzco, Arequipa y Cajamarca, el mensaje de la cultura barroca se difundió simultáneamente en el exterior de las iglesias mediante las portadas y en su interior a través de los retablos dorados; las dos grandes expresiones de la arquitectura barroca. Por el contrario en otras ciudades virreinales como Ayacucho y Trujillo, la persuasión retórica se refugió solamente en los retablos dentro de las iglesias; la ausencia de portadas-retablos barrocos en estas dos ciudades estaría manifestando que no había nada de qué persuadir a los vecinos apenas salían de las iglesias a la calle y transitaban por el exterior hacia sus casas.

En algunos pueblos andinos los habitantes solo recibirían la persuasión retórica por intermedio de los retablos barrocos dentro de las iglesias, pero quedaban desamparados de dicha persuasión los vecinos de numerosos otros pueblos a los que no llegaron los retablos barrocos, y mucho menos las portadas-retablos del período barroco dieciochesco. Durante ese período, dentro de la misma diócesis eclesiástica del Cuzco, los cuzqueños recibían el mensaje de vida religiosa desde unas portadas arquitectónicamente diferenciadas de las portadas también barrocas que persuadían retóricamente en la misma concepción de vida a los vecinos de los pueblos rurales de Lampa, Ayaviri y Asillo. Y todavía más, dentro de esa misma diócesis, los vecinos de Manara, Ayrihuanca, Haquira y Llac-Hua eran persuadidos retóricamente por portadas de una conformación arquitectónica y de una ostentación decorativa diferentes de las que comunicaban retóricamente la misma concepción cultural a los vecinos de Lampa, Ayaviri y Asillo.

La correlación entre la arquitectura virreinal como patrimonio cultural diferenciado en escuelas regionales y la cultura homogénea virreinal vigente durante el período del barroco aparece interrelacionada por un entreverado de conexiones contradictorias y antitéticas, que son verdaderas relaciones aporéticas. Una misma cultura sería persuadida retóricamente desde el patrimonio cultural de la arquitectura diferenciada en las escuelas arquitectónicas regionales y difundida diversificadamente por los pueblos y ciudades del virreinato del Perú.

\section{LAS ARQUITECTURAS VIRREINALES $Y$ LAS CULTURAS VIRREINALES}

La arquitectura virreinal peruana es en sí misma un objeto elaborado en una época histórica determinada y perdura como el patrimonio de la cultura en la que fue construida. Podemos definir que esta arquitectura constituye una parte 
muy importante del patrimonio cultural objetivado que nos queda del período virreinal. Aunque hablemos en conjunto de este patrimonio cultural objetivo que es la arquitectura virreinal, en realidad existieron expresiones arquitectónicas diferenciadas y autónomas, localizadas en las escuelas regionales, que difieren no solo por el período cronológico asincrónico en que surgieron, sino especialmente por su conformación estructural y el recubrimiento decorativo.

Podemos colocar frente a frente como netamente diferenciadas la arquitectura barroca del Cuzco, desarrollada durante la segunda mitad del siglo XVII, y la arquitectura planiforme de Arequipa y del Collao, desplegada durante las dos mitades del siglo XVIII hasta sus últimas décadas, y recubiertas por una decoración totalmente inexistente en el área del gran barroco cuzqueño. Analicemos ahora correlativamente estas dos escuelas arquitectónicas regionales como representativas del patrimonio cultural peruano.

Los historiadores de la arquitectura virreinal peruana se enfrentan a estas diferencias notorias y generalizadas entre las dos escuelas regionales y tratan de interpretarlas desde posiciones estrictamente arquitectónicas. El norteamericano George Kubler pretendió desglosar la terminología de "estilo mestizo", atribuida desde la década de 1920 a la arquitectura arequipeña y collavina, e introdujo en su lugar la clasificación terminológica culturalmente aséptica de arquitectura metropolitana - aplicada a la del Cuzco y a la de Lima- y arquitectura provinciana y popular, en la que incluía la de Arequipa, la del Collao y también la de Cajamarca. Sin embargo el problema no es exclusivamente terminológico, sino también y fundamentalmente de enraizamiento de estas escuelas regionales en una fundamentación cultural apropiada.

Desde los estudios iniciales sobre la arquitectura planiforme surperuana de Arequipa y el Collao, los historiadores propusieron la teoría del Ilamado "estilo mestizo", en el que hacen coexistir unas formas arquitectónicas españolas y una decoración indígena andina, de lo que resultaba la fusión cultural hispano-indígena. El clásico Wethey distinguía dos grupos diferentes de arquitectura virreinal peruana: un primer grupo de la considerada por él como española pura, que comprendía el gran barroco cuzqueño, a la que otorgaba carácter propiamente español, aunque la reconocía como "colonial" virreinal10; y un segundo grupo de la arquitectura planiforme surperuana, constituido por la fusión de lo europeo con la aportación de los elementos decorativos y las técnicas bidimensionales de tallado, propios de la cultura autóctona indígena.

Se ha empleado la palabra "fusión" para explicar la presencia de los dos componentes de distinta procedencia cultural en la arquitectura planiforme surperuana pero acaso no sea ella la más adecuada porque -según las interpretaciones de los historiógrafos partidarios del llamado "estilo mestizo" - cada uno de ellos conservaba en esta arquitectura andina arequipeña-collavina su propia raigambre cultural, de modo que lo arquitectónico continuaba siendo español y lo decorativo expresaba la cultura indígena nativa, de la que procede.

En sus diversos estudios reivindicativos del "estilo mestizo", Teresa Gisbert lo definía de este modo: "arquitectónicamente el estilo mestizo consiste en la aplicación de una decoración peculiar a las formas estructurales europeas"11. La inclusión del factor diferenciador consistente en "el componente indigena"12 lo convertiría en un estilo distinto del barroco europeo.

De acuerdo con estas interpretaciones historiográficas, sería más preciso considerar este estilo surperuano andino como la coexistencia simultánea en unas mismas portadas andinas planiformes de dos elementos de distinta naturaleza cultural: lo español y lo indígena. El término "fusión" parece indicar, por el contrario, que los dos componentes modificarían su propia naturaleza

11 Teresa Gisbert. "El barroco andino y el estilo mestizo". En Simposio Internacional sobre el Barroco Latinoanericano. Roma 1984, tomo II, p. 143.

12 Ibidem, p. 137 
originaria para transformarse dentro de la arquitectura virreinal planiforme en un tercer conjunto distinto de ellos, que sería el resultante de la presunta fusión. Pero no es tal transformación en algo diferente lo que vienen definiendo los historiógrafos partidarios del "estilo mestizo", sino la permanencia de cada componente manteniendo su propia raigambre cultural, junto al otro componente también invariado culturalmente.

Estas someras referencias a las interpretaciones historiográficas convencionales sobre el llamado "estilo mestizo" surperuano-potosino nos permite retomar, bajo una nueva claridad, el tema de la arquitectura virreinal como objeto de patrimonio cultural. Según las interpretaciones usuales del "estilo mestizo", en las portadas planiformes arequipeñas y collavinas coexistirian dos expresiones culturales diferentes: en cuanto a los componentes arquitectónicos serían un objeto cultural español, y en lo que respecta a la ornamentación y a su técnica de tallado constituirían un objeto cultural indígena muy peculiarmente característico. De tal modo que estas portadas planiformes andinas surperuanas consistirian en patrimonios culturales de dos procedencias fusionadas, en cuanto que en ellas coexistirían los dos elementos culturales antes mencionados de la procedencia cultural que han presupuesto los historiógrafos partidarios del "estilo mestizo".

El problema se complica radicalmente si tenemos en cuenta que la arquitectura planiforme se desarrolló en las dos regiones de Arequipa y del Collao sucesivamente, a lo largo de las dos mitades del siglo XVIII. Surge de inmediato la pregunta: ies posible que en una época tan tardía continuaran coexistiendo en vigencia inmodificada dos hechos culturales como serían una arquitectura española y una decoración indígena autóctona? La perduración así presupuesta teóricamente tendría sentido si a lo largo de los siglos XVI y XVII no hubiera acaecido en el virreinato del Perú ninguna evolución cultural, o bien más propiamente esa arquitectura planiforme hubiera reactualizado las condiciones culturales vigentes al momento de la conquista española, o a lo sumo hasta cumplidos los dos primeros tercios del siglo XVII.

En realidad, la arquitectura planiforme surperuana labrada durante el siglo XVIII corresponde a una situación cultural en la que lo español puro y lo indígena autóctono fueron superados evolutivamente, transformándose -mediante profundas $\mathrm{e}$ innovadoras evoluciones culturales- en otra concepción cultural distinta, que había dejado de ser lo español puro y lo indígena autóctono puro.

El planteamiento de los historiadores convencionales acerca del llamado "estilo mestizo" ha deducido una interpretación arquitectónica a partir de la teoría sociológica sobre el mestizaje cultural vigente durante la primera mitad del siglo $X X$. Partiendo del presupuesto de la dualidad entre la cultura española y la cultura indígena, como integrantes de la sociedad mestiza hispanoamericana, derivaron también la dualidad de los componentes de la arquitectura planiforme superuana referidos a esas dos culturas coexistentes en la cultura mestiza hispanoamericana, según las teorías sociológicas del siglo XX.

Por nuestra parte, seguimos un proceso deductivo de sentido inverso: partiendo desde los análisis arquitectónicos más estrictos, nos remontamos hasta la fundamentación cultural de esta arquitectura planiforme arequipeña-collavina. En trabajos publicados anteriormente ha sido expuesta esta interpretación arquitectónica y culturalista ${ }^{13}$.

Los pasos fundamentales de esta reinterpretación se ciñen al siguiente proceso teórico:

1. El componente arquitectónico de estas portadas planiformes surperuanas de Arequipa y el Collao no es en absoluto una expresión arquitectónica española y ni siquiera es una

13 Antonio San Cristóbal. La arquitectura planiforme y textilográfica virreinal de Arequipa. Lima, Facultad de Arquitectura, Universidad Nacional de San Agustin de Arequipa, 1997; Id. "Reinterpretación de la arquitectura planiforme". En Barroco iberoamericano. Territorio, arte, espacio y sociedad. Sevilla, Universidad Pablo de Olavide-Ediciones Giralda, 2001, Iomo II, pp. 1135-1154; Id. "Terminologia y concepto de la arquitectura planiforme". En Memoria del I Encuentro Internacional sobre Barroco Andino. La Paz, 2003, pp. 95-106. 
conformación renacentista arcaica en el siglo XVIII, reiterada estáticamente en una época tan tardía; tampoco es una arquitectura marginal y provinciana a la manera de los pueblos primitivos de la antigüedad clásica, como la consideraba Graciano Gasparini. La estructura arquitectónica de estas portadas planiformes corresponde a la más plena actualidad y contemporaneidad de los modelos arquitectónicos empleados durante el siglo XVIII, siempre según la autonomía diferenciada respecto de los modelos usuales en la arquitectura del Cuzco, en la escuela regional de Lima o en la de Cajamarca.

2. Los alarifes andinos de Arequipa y del Collao no se limitaron a incorporar una decoración de naturaleza cultural indígena autóctona sobre los modelos europeos asumidos pasivamente. Aquellos anónimos artífices ensambladores y talladores de las portadas planiformes crearon simultáneamente y con plena originalidad las portadas en su integridad. Es decir, son los autores tanto de la conformación arquitectónica como de la decoración tallada que las recubre de modo textilográfico. Las portadas de Arequipa-Collao son propiamente el resultado unitario de un proceso de creación original ejercido por los artífices andinos surperuanos sobre el conjunto de los componentes arquitectónicos, y de la decoración tallada según el modo planiforme tan distinto del relieve tridimensional barroco puro.

3. Una interpretación concordante con la unidad integral del componente arquitectónico y del decorativo, creados conjuntamente de modo original en estas portadas, ha de superar el dualismo de elementos de procedencia cultural heterogénea en que se habían estancado los historiógrafos convencionales: arquitectura española y decoración indígena. Este dualismo derivaba de las teorías sociológicas sobre la cultura mestiza vigentes hasta mediados del siglo $X X$, pero es inaplicable para la comprensión de la arquitectura planiforme surperuana andina. Reiteramos que esas portadas no contienen un elemento componente que pueda ser considerado como español, coexistente con otro apreciado como influencia indígena autóctona, a la manera que presuponía el clásico Wethey en 1949. La conformación arquitectónica de estas portadas planiformes expresa la más plena actualidad del siglo XVIII virreinal peruano, y es la creación original de los alarifes y talladores andinos.

4. Durante el período tardío desde finales del siglo XVII y durante casi todo el siglo XVIII surgió en la zona andina surperuana una cultura virreinal andina con expresiones diversas: la reactualización del aimara, el vestido, la religiosidad popular, etc. Esta cultura andina no es española ni indígena autóctona, es una nueva formación cultural andina surgida dentro del período avanzado del virreinato, y conforma propiamente una cultura virreinal, pero de diferente contenido de las culturas vividas en los centros urbanos de Lima y en ciudades como Cuzco, Ayacucho, Trujillo o Cajamarca. Precisamente una de las expresiones culturales más resaltantes de esta cultura andina virreinal es la arquitectura planiforme surperuana arequipeña-collavina.

De todas estas premisas desarrolladas ampliamente en los estudios antes mencionados concluimos que la escuela regional de la arquitectura planiforme representa el patrimonio cultural objetivo correspondiente a la cultura andina virreinal del siglo XVIII, en cuyo marco fue creada, con la aceptación connatural de los pobladores andinos imbuidos de esta cultura virreinal.

La cosmovisión dualista atribuida por los expositores convencionales a la arquitectura planiforme arequipeña-collavina ha sido ahora desplazada, según las exposiciones antes desarrolladas, por la conformación unitaria integral, creada original y conjuntamente por los alarifes y talladores andinos dieciochescos. Esta arquitectura planiforme se nos presenta como el patrimonio cultural objetivo surgido de esta cultura andina virreinal, también ella misma unitaria en sus componentes. La corrección entre la arquitectura planiforme y la cultura andina virreinal que la ha producido desvanece por su propia coherencia esa otra dualidad cultural integrada por lo español y lo indígena autóctono 
que proponía la tesis del llamado "estilo mestizo". La arquitectura planiforme arequipeña-collavina subsiste todavía en la región surandina del Perú como el patrimonio cultural objetivado por la cultura andina virreinal.

Retornamos ahora a esa visión amplia de la arquitectura virreinal peruana con la que se iniciaba este apartado. La arquitectura en su conjunto está fragmentada en escuelas arquitectónicas regionales que podemos agrupar en dos grandes conformaciones: las escuelas barrocas no-planiformes y la escuela planiforme de Arequipa-CoIlao. Escuelas que no muestran los rasgos de lo planiforme son la de Lima, la del Cuzco, la de Cajamarca o la de las tierras altas surperuanas (Lampa-Ayaviri-Asillo-Tisco).

Existió ciertamente una influencia indígena de carácter prehispánico en la arquitectura del gran barroco del Cuzco, consistente en la técnica de tallar la dura piedra andesita, empleada por los canteros indígenas cuzqueños para labrar las portadas barrocas de la ciudad. Pero es una aportación transparente, que no se manifiesta objetivada como tal ni en la conformación del diseño, ni en la complementación decorativa de esas portadas, y que por el contrario deja ver únicamente la estructura arquitectónica y ornamental del gran barroco cuzqueño de carácter urbano, como las otras escuelas regionales virreinales. No consideramos, pues, el gran barroco del Cuzco de la segunda mitad del siglo XVII como una arquitectura indígena autóctona, sino como virreinal no-planiforme, a la manera de las otras arquitecturas regionales incluidas en el mismo grupo.

También estas arquitecturas virreinales no-planiformes expresan actualmente el patrimonio cultural objetivo de naturaleza virreinal, solo que corresponden como creaciones culturales a una cultura virreinal propia de las poblaciones urbanas como Lima, Cuzco, etc. Son, pues, el patrimonio cultural representativo de la cultura virreinal urbana de mayor extensión en el virreinato del Perú.
La arquitectura virreinal planiforme, que representa el patrimonio cultural de la cultura andina virreinal floreciente durante el siglo XVIII en la región andina surperuana, coexistió durante algún tiempo con este patrimonio urbano.

Los historiadores de la arquitectura virreinal peruana han distinguido con toda precisión estas dos conformaciones arquitectónicas: la no-planiforme y la planiforme. Resulta de suyo obvio que concentren sus exposiciones y análisis solo y exclusivamente en lo que concierne a la arquitectura como objetividad específica, ya que este es el objeto de la ciencia que ellos cultivan. Si ampliamos el análisis a una visión interdisciplinaria que abarque simultáneamente la arquitectura y la cultura asociada a ella, proponemos que no se trata solo de dos expresiones arquitectónicas autónomas y diferenciadas, en cuanto a sus características. Ambas modalidades, consideradas desde una visión culturalista, son también dos objetividades como patrimonio cultural, representativas de dos culturas virreinales coexistentes durante el siglo XVIII. Cabe enfatizar que aun cuando hablamos de las dos expresiones arquitectónicas como patrimonios culturales objetivos de diferentes extracciones culturales, no por eso fragmentamos arbitrariamente la unidad cultural del virreinato del Perú.

Podemos señalar todavía otra diferenciación dentro de la arquitectura planiforme andina, en cuanto se distinguen en ella grupos regionales de portadas, como las de Arequipa, las de Apurímac, las de Chumbivilcas-Coporaque de Espinar, las del Collao y las de Potosí. Difieren estos grupos de portadas por razón de la composición de su diseño, por los motivos ornamentales que las adornan y por la sutil multiplicidad en cuanto a las técnicas de tallar la decoración, como lo he expuesto en otros estudios publicados anteriormente ${ }^{14}$. Sin embargo, estos múltiples núcleos de portadas planiformes andinas no rompen la unidad de esta escuela regional surperuana, porque preservan un conjunto de características comunes, como el tallado planiforme de la decoración y la distribución textilográfica de los

14 Antonio San Cristobal. "Unidad o heterogeneidad del estilo mestizo surperuano". En I Encuentro Internacional de Peruanistas, Lima, Universidad de Lima, 1998, Iomo II, pp. 139.155; id. "Grupos regionales de portadas planiformes". En Sonia Tello Rozas. En tomo al patrinionio e interdisciplinariedad. Encuentro Iberoamericano Forun Unesco. Lima, Universidad de San Martin de Porres, 2002, pp. 233-267. 
ornamentos, que son específicos dentro de la arquitectura virreinal peruana y diferenciados respecto de las otras escuelas regionales.

A pesar de la diferenciación de estos grupos de portadas surperuanas andinas, todos ellos integran la escuela surperuana planiforme y como tales corresponden a la misma cultura andina virreinal; por consiguiente conforman un patrimonio cultural objetivo unitario. Solo persiste, pues, la dualidad de dos patrimonios culturales antes diferenciados: el que representan las portadas planiformes surperuanas andinas y el que representa la arquitectura no-planiforme. Las dos modalidades arquitectónicas expresan como patrimonios culturales objetivos la doble cultura vigente en el virreinato del Perú durante el siglo XVIII.

La cultura andina virreinal y su objetividad patrimonial consistente en la arquitectura planiforme arequipeña-collavina surgieron en el virreinato del Perú como un desarrollo diferenciado dentro de la amplia cultura de la época. No interpretamos ahora cómo y por qué surgió esta cultura andina virreinal dentro de la unidad administrativa, de gobierno, de economía y de religión en que se basaba el virreinato del Perú. Simplemente señalamos el he- cho histórico y existencial que reconoce el surgimiento de la cultura virreinal andina de la que es patrimonio cultural la arquitectura planiforme.

Si la dualidad existencial de la arquitectura virreinal no-planiforme y de la arquitectura planiforme andina surperuana no fragmenta el conjunto unitario de la arquitectura virreinal peruana, tampoco la dualidad de los dos patrimonios culturales objetivados en estas modalidades arquitectónicas fragmenta, como se ha dicho, la unidad de la cultura del virreinato del Perú.

Desde esta amplia visión de las dos conformaciones arquitectónicas y de los dos patrimonios culturales representativos de las dos culturas vigentes en la vasta unidad del virreinato peruano, podría también interpretarse ahora la función retórica persuasiva de una religiosidad cultural andina surperuana transmitida desde los diferentes grupos de las portadas planiformes antes señalados hacia los habitantes de toda la región geográfica de Arequipa-Chumbivilcas-ApurímacCollao durante el período del siglo XVIII, cuando estaban vigentes esa cultura y su arquitectura planiforme característica. Quede esta tarea para el lector del presente artículo. 